\title{
AVALIAÇÃO FÍSICO-QUÍMICA E MICROBIOLÓGICA DE EFLUENTES E REJEITO DE MINA DE EXTRAÇÃO DE URÂNIO
}

\author{
E. F. RIBEIRO ${ }^{1 *}$, H. AZEVEDO ${ }^{2}$, C. V. ROQUE ${ }^{2}$, A. L. BRUSCHI ${ }^{2}$ \\ ${ }^{1}$ Universidade Estadual Paulista "Júlio de Mesquita Filho", Departamento de Engenharia e \\ Tecnologia de Alimentos \\ ${ }^{2}$ Laboratório de Radioecologia da Comissão Nacional de energia Nuclear LAPOC/CNEM \\ e-mail: elisa_frib@hotmail.com
}

\begin{abstract}
RESUMO
Atividades de mineração em áreas que contêm minerais sulfetados como a pirita $\left(\mathrm{FeS}_{2}\right)$, podem expor à atmosfera os sulfetos confinados a matriz rochosa, que ao entrarem em contato com a água e ar, sofrem processo de oxidação catalisado por bactérias, principalmente do gênero Acidithiobacillus. Os produtos da oxidação dos sulfetos, além de serem altamente solúveis, apresentam reação fortemente ácida, de modo que são facilmente dissolvidos na fase líquida, acidificando as águas de drenagem. O objetivo deste trabalho foi avaliar a composição física, química e microbiológica de efluentes e rejeito de uma mina de urânio em fase de descomissionamento. Os resultados mostraram que os locais de armazenamento de efluentes radioativos apresentaram elevadas concentrações de espécies químicas esperadas bem como de metais. A presença de A. ferrooxidans e A. thiooxidans, estiveram relacionados aos altos valores de força eletromotriz, já os baixos valores de $\mathrm{pH}$ indicaram a ocorrência de drenagem ácida de mina nos locais e ação de bactérias lixiviantes.
\end{abstract}

\section{INTRODUÇÃO}

As atividades de mineração têm contribuído significativamente para o crescimento e desenvolvimento de vários países. Em relação às preocupações frente aos impactos causados pela exploração mineral, a questão da água e dos recursos hídricos é, com frequência, um dos pontos de conflitos mais importantes que envolvem a mineração e a sociedade, visto que tais atividades envolvem grandes modificações no contorno da paisagem, podendo ainda promover alterações químicas, físicas e biológicas no ambiente (ANTUNES et al, 2007).

$\mathrm{Na}$ região do Planalto de Poços de Caldas está localizada a primeira mina de extração de minério de urânio a ter sua jazida explorada no Brasil, Mina de Urânio Osamu
Utsumi, a qual teve suas atividades de exploração mineral iniciadas em 1982, com produção total de 1.030 tU até 1995 (CIPRIANI, 2002). Essa mina está localizada nas dependências da Unidade de Trtamento de Minérios das Indústrias Nucleares do Brasil (UTM/INB)

Nessa área mineradora, efluentes radioativos são gerados por drenagem ácida de mina (DAM), os quais são tratados quimicamente com hidróxido de cálcio e floculantes, para serem posteriormente lançados em um corpo aquático situado na Sub-bacia Hidrográfica do Ribeirão das Antas, ou seja, na represa das Antas.

Para que a DAM ocorra é fundamental a presença de sulfeto metálico associado ao minério. $\mathrm{O}$ mineral sulfetado sofre processo de oxidação natural e, em contato com a água 
da chuva ou umidade, produz ácido sulfúrico que dilui-se na água e solubiliza metais presentes na matriz rochosa.

Nas dependências da UTM/INB a ocorrência de DAM é explicada pela oxidação natural do sulfeto metálico pirita $\left(\mathrm{FeS}_{2}\right)$ que ao entrar em contato com a água e oxigênio leva a formação de ácido sulfúrico que ao diluir-se na água promove a solubilização dos metais presentes na rocha, caracterizando um efluente com elevada acidez e metais solúveis. Cabe ressaltar, que a composição do efluente, tais como tipo de materiais, presença ou ausência de radionuclídeos, depende diretamente da composição da rocha e do tipo de exploração mineral em questão (CAMPOS et al., 2010; CAMPOS, 2006; LYEW et al., 2001). Os metais são transportados através da drenagem dessas águas e quando alcançam os corpos de água e os lençóis freáticos acabam comprometendo a qualidade dos mesmos, impedem os seus usos e alteram a flora e a fauna aquáticas presentes (REBOUÇAS; BRAGA; TUNDISI, 2006).

Os minerais sulfetados podem causar sérios problemas ambientais através da lixiviação catalisada por bactérias, as quais mobilizam os metais que podem ser introduzidos no solo ou até mesmo no lençol freático, se a base da pilha de rejeitos for permeável (SCHIPPERS et al., 1995).

\section{As bactérias Acidithiobacillus} ferrooxidans e Acidithiobacillus thiooxidans são considerados os microrganismos mais importantes na dissolução bacteriana de metais sulfetados (biolixiviação). Estas duas espécies do gênero Acidithiobacillus são bactérias do tipo gram-negativo, aeróbias e quimioautotróficos. Crescem em temperatura média de $25^{\circ} \mathrm{C}$ (bactérias mesofílicas) e são comuns em ambientes ácidos. Tais bactérias podem crescer usando a energia obtida pela oxidação de compostos de enxofre reduzidos e também são capazes de oxidar o íon ferroso (GARCIA, 1989).
O processo de lixiviação bacteriana (biolixiviação) é um fenômeno químico, no entanto, também pode ser considerado como um processo eletroquímico, pois ocorre transferência de elétrons do mineral para o microrganismo (TEIXEIRA et al., 2002). Isso consiste em uma série de reações químicas e bioquímicas que solubilizarão o metal de forma direta, quando a própria bactéria ataca o sulfeto ou, de forma indireta, quando os produtos do metabolismo bacteriano atuam sobre o sulfeto metálico (SCHIPPERS et al., 1995).

Dessa forma, foram realizadas amostragens de água procedentes de efluentes e rejeito de uma mina de extração de minério de urânio, as quais foram submetidas a análises das concentrações de metais, nutrientes e materiais em suspensão bem como a presença das bactérias Acidithiobacillus ferrooxidans e Acidithiobacillus thiooxidans, a fim de avaliar a composição dos efluentes gerados pelo pela UTM/INB.

\section{MATERIAIS E MÉTODOS}

\subsection{Local de amostragem}

No presente estudo foram realizadas coletas de amostras de água na represa das Antas, bem como de efluentes e rejeito na UTM/INB. Na UTM/INB foram coletadas amostras em três locais: o ponto D3, o ponto Cava da Mina (CM) e o ponto BS (Borra de Enxofre). Já na represa das Antas o ponto de amostragem foi o ponto 14 que corresponde à região limnética, próximo à barragem. Estima-se que, $94,5.10^{6}$ ton. de rocha já foram removidas, devido à mineração de urânio, sendo que somente $2 \%$ desta quantidade foi destinada ao processamento físico e químico. O restante permanece estocado principalmente em pilhas de rejeito de mineração, ou seja, no bota-fora $4(\mathrm{BF} 4) \mathrm{e}$ bota-fora 8 (BF8). 
O processo de extração do urânio a partir do minério produziu grandes quantidades de rejeitos sólidos e efluentes líquidos, os quais são tratados por neutralização com carbonato de cálcio $\left(\mathrm{CaCO}_{3}\right)$ e óxido de cálcio $(\mathrm{CaO})$ até atingir $\mathrm{pH}=9,0$ e, então, descartados em bacia de rejeito para deposição dos sólidos. Durante os períodos em que a usina não está processando minério, a água da bacia de rejeitos continua sendo mantida em pH alcalino pela adição de carbonato de cálcio. A cabeceira da bacia de rejeitos apresenta uma região desprovida de lâmina de água, onde se situa deposição de borra de enxofre, procedente da usina de fabricação de ácido sulfúrico (ponto BS).

\subsection{Determinações físico-químicas}

2.2.1 Concentração de oxigênio dissolvido, potencial hidrogeniônico e força eletromotriz (potencial de óxido-redução)

O potencial de óxido-redução foi determinado no laboratório, utilizando-se eletrôdo de $\mathrm{Pt}$ (contra $\mathrm{Ag}^{0} / \mathrm{AgCl}$ de referência), equipamento Metrohm Herisau e para as determinações do $\mathrm{pH}$ utilizou-se eletrôdo V - 620 Analison, equipamento Digimed. A concentração de oxigênio dissolvido foi determinada utilizando-se um oxímetro marca WTW, modelo Oxi $315 \mathrm{i}$.

\subsubsection{Concentração de material em suspensão}

Para as determinações da concentração de material em suspensão foi utilizado o método gravimétrico descrito em Teixeira, Tundisi e Kutner (1965). Primeiramente as membranas a serem utilizadas para filtragem foram colocadas em estufa a $450{ }^{\circ} \mathrm{C}$ e então pesadas (P1). Um volume conhecido de amostra foi filtrado com auxílio de uma bomba de sucção a vácuo, utilizando-se os filtros específicos, e estes então, contendo material total, foram colocados em estufa a $110{ }^{\circ} \mathrm{C}$ por 24 horas e após sendo transferidos para um dessecador (1 hora) e depois pesados em balança analítica da marca Gehaka (modelo AG 200), determinando-se assim o P2 (sólidos totais + filtro). Para obtenção da concentração de material em suspensão foi feita a diferença entre os pesos P2 e P1. Posteriormente, os filtros foram novamente calcinados em mufla a $450{ }^{\circ} \mathrm{C}$ por $1 / 2$ hora para "queimar" a matéria orgânica, transferidos para o dessecador (1 hora) e pesados novamente, o que correspondeu ao peso das cinzas (inorgânicos + filtro) (P3). Assim, o peso dos sólidos inorgânicos é calculado através da diferença entre P3 e P1. Portanto, a diferença entre os sólidos em suspensão e os sólidos inorgânicos representa a quantidade de matéria orgânica.

2.2.3 Dureza, sulfato, urânio, tório e metais totais (Al, As, $\mathrm{Mo}, \mathrm{Fe}^{2+}, \mathrm{Fe}^{3+}, \mathrm{As}, \mathrm{Pb}, \mathrm{Cr}, \mathrm{Cu}$, $\mathrm{Mn}$, e Zn)

A determinação dos valores de dureza (cálcio e magnésio) foi realizada por espectrometria de absorção atômica por plasma acoplado indutivamente (Varian modelo Lierty RL Sequencial ICP-OES). As análises de sulfato foram realizadas por espectrofotometria UV-Visível e segundo a metodologia descrita em ASTM (1980).

Para o elemento químico urânio, alíquotas da amostra na concentração de 2,5 a $12,5 \mathrm{mg} \cdot \mathrm{L}^{-1}$ que se refere ao intervalo da curva padrão foram tratadas por extração utilizando-se solvente tributilfosfato como reagente, submetidas a uma reação com solução do reagente colorimétrico de Arsenazo III e medida no comprimento de onda de $650 \mathrm{~nm}$ em espectofotômetro UVVisível. Na determinação das concentrações do elemento tório, alíquotas da amostra na concentração de 1,6 a $8,0 \mathrm{mgL}^{-1}$ que se refere ao intervalo da curva padrão foram tratadas por extração utilizando-se solvente topotrioctilfosfina, submetidas a uma reação com solução do reagente colorimétrico de Arsenazo III, em seguida foram medidas no comprimento de onda de $665 \mathrm{~nm}$ em 
espectrofotômetro UV-Visível (FUKUMA et al., 2001).

Para a determinação dos metais totais $\left(\mathrm{Fe}^{2+}, \mathrm{Fe}^{3+}, \mathrm{Mo}, \mathrm{As}, \mathrm{Pb}, \mathrm{Cr}, \mathrm{Cu}, \mathrm{Mn}\right.$, e $\left.\mathrm{Zn}\right)$ amostras foram armazenadas em garrafas de poliestireno e fixadas com ácido nítrico ultrapuro a uma concentração final de 0,2 M. A digestão das amostras foi realizada de acordo com metodologia descrita em APHA (1992), e a determinação das concentrações foram efetuadas por espectrofotometria de absorção atômica para $\mathrm{As}$ e $\mathrm{Fe}^{3+}$, por espectrofotometria UV-Visível para $\mathrm{Fe}^{2+}$, e por espectrofotometria por plasma-ICP para os demais elementos.

\subsubsection{Concentração de Nutrientes}

Para as determinações das concentrações de nutrientes, amostras foram coletadas utilizando-se uma garrafa vertical, de um litro, do tipo Van Dorn para coleta na superfície da coluna d'água com base nas seguintes metodologias: para nitrito e silicato a técnica descrita por Golterman, Clymo e Ohnstad (1978); para nitrato e nitrogênio total a metodologia descrita por Mackereth, Heron e Tailing (1978); para amônio o método descrito por Koroleff (1976); para fósforo total a técnica descrita por Valderrama (1981) e para fosfato total dissolvido e fosfato inorgânico a metodologia descrita em Strickland e Parsons (1960).

\subsection{Determinações microbiológicas - Detecção e contagem de bactérias}

\subsubsection{Detecção de Acidithiobacillus} ferrooxidans e Acidithiobacillus thiooxidans

Para a análise de $A$. ferrooxidans e $A$. thiooxidans foram coletadas $100 \mathrm{~mL}$ de amostra de cada ponto, obtidas com garrafas de Van Dorn. Para estimar a densidade de A.ferrooxidans e A.thiooxidans foi utilizada a técnica do Número Mais Provável (NMP). A técnica do número mais provável tem sido a mais amplamente utilizada para verificar a ocorrência de Acidithiobacillus spp. a partir de amostras ambientais (SCHIPPERS et al, 1995).

A partir da amostra sólida, procedente do ponto $\mathrm{BS}$, foram tomados $10 \mathrm{~g}$, os quais foram diluídos em água destilada esterilizada (1:10, 1:100 e 1:1000), pH 1,8. Em seguida, as amostras assim preparadas foram colocadas sob agitação em "shaker" (200 rpm) durante 1 hora, à temperatura ambiente, a fim de facilitar a separação de células aderidas ao material.

Cada amostra, dos quatro pontos de coleta, foi inoculada em erlenmeyers contendo meio $\mathrm{T} \& \mathrm{~K}$, sendo realizada em triplicata, visando determinar a ocorrência dos Acidithiobacillus spp. Para determinação de A. ferrooxidans, foram adicionados $10 \mathrm{~mL}$ de solução contendo $\mathrm{Fe}^{2+}$ filtrado, como fonte energética, ao meio de cultura basal, $\mathrm{pH}$ 1,8 (TUOVINEN; KELLY, 1973). Entretanto, para a ocorrência de A. thiooxidans, a fonte energética adicionada ao meio basal, $\mathrm{pH} 2,8$, foi o enxofre elementar.

As amostras assim preparadas foram incubadas a temperatura ambiente, cerca de $25^{\circ} \mathrm{C}$ por 21 dias. Após período de incubação, a ocorrência de $A$. ferrooxidans e $A$. thiooxidans foi avaliada através da observação visual, verificando-se a presença de ferro férrico $\mathrm{Fe}^{3+}$ e de $\mathrm{S}^{2+}$ precipitados no fundo do frasco respectivamente, os quais apresentam cores características.

\subsubsection{Contagem de Bactérias Heterotróficas}

O meio de cultura sólido CPS foi utilizado para a contagem total de bactérias heterotróficas aeróbias. A partir da amostra coletada foram realizadas diluições seriadas (1:10, 1:100 e 1:1000) em água destilada esterilizada. Em seguida, a partir de cada amostra e diluição acima descrita foram inoculadas, em triplicata, $0,1 \mathrm{~mL}$ em meio CPS, utilizando-se o método de espalhamento em superfície com auxílio da alça de 
Drigalski. Em seguida, incubou-se a $30^{\circ} \mathrm{C}$ por 10 dias.

\section{RESULTADOS E DISCUSSÃO}

\subsection{Oxigênio dissolvido, sólidos totais e sólidos orgânicos em suspensão}

Os resultados obtidos para concentração de oxigênio dissolvido e sólidos em suspensão estão representados na Tabela 1 .

Os valores referentes à concentração de oxigênio dissolvido variaram de $4,0 \mathrm{mg} \mathrm{L}^{-1}$ no ponto D3 a $5,8 \mathrm{mg} \mathrm{L}^{-1}$ no ponto 14. Já os valores obtidos para sólidos totais em suspensão variaram de $3,6 \mathrm{mg} \mathrm{L}^{-1}$ (ponto 14) a $17,8 \mathrm{mgL}^{-1}(\mathrm{D} 3)$, observando-se que a fração orgânica representou uma parcela menor da parte total dos sólidos nos 3 pontos analisados.

Tabela 1 - Valores médios da concentração de oxigênio dissolvido e de sólidos em suspensão presente nas amostras

\begin{tabular}{cccc}
$\begin{array}{c}\text { Pontos de } \\
\text { Amostra- } \\
\text { gem }\end{array}$ & $\begin{array}{c}\mathbf{O}_{\mathbf{2}} \\
(\mathbf{m g} / \mathbf{L})\end{array}$ & $\begin{array}{c}\text { Sólidos } \\
\text { totais em } \\
\text { suspensão } \\
(\mathbf{m g} / \mathbf{L})\end{array}$ & $\begin{array}{c}\text { Sólidos } \\
\text { orgânicos em } \\
\text { suspensão } \\
(\mathbf{m g} / \mathbf{L})\end{array}$ \\
\hline $\mathrm{CM}$ & 4,9 & 10,8 & 1,8 \\
$\mathrm{D} 3$ & 4,0 & 17,8 & 3,2 \\
14 & 5,8 & 3,6 & 1,6 \\
\hline
\end{tabular}

\subsection{Dureza, sulfato, urânio e tório}

De acordo com a Tabela 2, os resultados referentes aos valores para a concentração de sulfato variaram de $3,82 \mathrm{mg}$ $\mathrm{L}^{-1}$ (ponto 14) e 1142,0 $\mathrm{mg} \mathrm{L}^{-1}$ (ponto D3).

Para o elemento químico urânio houve registro de maior concentração também no ponto D3, cujo valor foi $5,69 \mathrm{mg} \cdot \mathrm{L}^{-1}$. Por outro lado, o ponto 14 apresentou o menor valor registrado, ou seja, $0,008 \mathrm{mg} \cdot \mathrm{L}^{-1}$. Em relação ao tório, maiores concentrações foram encontradas nos pontos D3 e CM, correspondendo aos valores $0,156 \mathrm{mg} \mathrm{L}^{-1} \mathrm{e}$
$0,130 \mathrm{mg} \mathrm{L}^{-1}$ respectivamente, e a menor concentração foi obtida no ponto D3, o qual apresentou um valor menor que $0,007 \mathrm{mg} \mathrm{L}^{-1}$ do radionuclídeo. Deve-se considerar que, uma vez que o ponto CM e D3 correspondem a locais de armazenamento de efluentes radioativos com drenagem ácida, elevadas concentrações de espécies químicas estáveis e radioativas eram esperadas.

Tabela 2 - Valores médios correspondentes a dureza, concentração de sulfato, urânio e tório em mg. $L^{-1}$.

\begin{tabular}{lllll}
\hline $\begin{array}{l}\text { Pontos de } \\
\text { Amostra- } \\
\text { gem }\end{array}$ & $\begin{array}{l}\text { Dureza } \\
\left(\mathbf{C a}+\mathbf{S O}_{\mathbf{4}}{ }^{2-}\right.\end{array}$ & $\mathbf{U}$ & $\mathbf{T h}$ \\
\hline & & & & \\
$\mathbf{M g})$ & & & & \\
$\mathbf{D 3}$ & 154,26 & 734,06 & 1,27 & 0,130 \\
$\mathbf{1 4}$ & 87,12 & 1142,0 & 5,69 & 0,156 \\
& 1,67 & 3,82 & $<0,008$ & $<0,007$ \\
\hline
\end{tabular}

3.3 Metais totais: $\mathrm{Mo}, \mathrm{Al}, \mathrm{As}, \mathrm{Pb}, \mathrm{Cr}, \mathrm{Cu}$, $\mathrm{Mn}, \mathrm{PO}_{4}{ }^{3-}$ e $\mathrm{Zn}$

Os valores encontrados para concentração de metais na UTM/INB, apresentados na Tabela 3, mostraram valores elevados de manganês nos pontos CM e D3, e uma alta concentração de zinco no ponto D3. Os valores de manganês e zinco registrados em amostras dos pontos CM e D3 mostram necessidade do tratamento destes efluentes antes do lançamento para o meio ambiente, uma vez que o limite para manganês e zinco previsto para o lançamento de efluentes (Resolução $n^{\circ} 430$, CONAMA, 2011) é de 1,0 $\mathrm{mg} \mathrm{L}^{-1}$ e 5,0 $\mathrm{mg} \mathrm{L}^{-1}$, respectivamente. Já o ponto 14, o qual está localizado já no ambiente deve conter concentrações dentro dos limites previstos para água Classe II (Resolução $\mathrm{n}^{\circ}$ 357, CONAMA, 2005). Os resultados mostraram que os valores registrados no ponto 14 atendem a Resolução 375 do CONAMA. 
Tabela 3 - Valores da concentração dos metais molibdênio (Mo), alumínio (Al), Arsênio (As), chumbo $(\mathrm{Pb})$, cromo $(\mathrm{Cr})$, cobre $(\mathrm{Cu})$, manganês $(\mathrm{Mn})$ e zinco $(\mathrm{Zn}) \mathrm{em} \mathrm{mg} \cdot \mathrm{L}^{-1}$.

\begin{tabular}{|c|c|c|c|c|c|c|c|c|c|}
\hline Pontos de Amostragem & Mn & Al & As & $\mathbf{Z n}$ & Mo & $\mathbf{C r}$ & $\mathrm{PO}_{4}{ }^{3-}$ & $\mathbf{C u}$ & $\mathbf{P b}$ \\
\hline $\mathrm{CM}$ & 22,4 & 23,9 & 0,005 & 1,64 & $<0,2$ & $<0,04$ & $<1$ & 1,3 & $<0,3$ \\
\hline D3 & 73,4 & 111,0 & 0,007 & 7,58 & $<0,2$ & $<0,05$ & $<1$ & 0,341 & $<0,3$ \\
\hline 14 & 0,270 & 0,192 & $<0,003$ & $<0,05$ & $<0,2$ & $<0,04$ & $<1$ & $<0,05$ & $<0,3$ \\
\hline Limite CONAMA 357/05 & 1,0 & - & 0,069 & 0,12 & - & 1,1 & 0,186 & $7,8^{*}$ & 0,210 \\
\hline Limite CONAMA 430/11 & 1,0 & - & 0,5 & 5,0 & - & 1,1 & - & 1,0 & 0,5 \\
\hline
\end{tabular}

\subsection{Potencial hidrogeniônico, força eletromotriz, concentração de $\mathrm{Fe}^{2+}$ e $\mathrm{Fe}^{3+} \mathrm{e}$ ocorrência de Acidithiobacillus spp.}

A análise dos resultados obtidos a partir das medições de $\mathrm{pH}$ mostrou que das 4 amostras coletadas, os pontos CM, D3 e BS apresentaram $\mathrm{pH}$ ácido, variando de 2,8 (ponto CM) a 3,9 (ponto BS). O ponto 14 foi o que apresentou valor de $\mathrm{pH}$ próximo a neutralidade, correspondente a 6,37 (Tabela 4). Em relação à ocorrência de Acidithiobacillus spp., no ponto $\mathrm{CM}$ foi encontrada maior concentração de Acidithiobacillus ferrooxidans enquanto a presença de Acidithiobacillus thiooxidans foi maior no ponto BS, com valores referentes a 0,9 e 4,3 NMP/ml, respectivamente.

De acordo com os resultados obtidos durante o presente estudo pode-se verificar que houve correlação entre a ocorrência de $A$. thiooxidans, A. ferrooxidans e os valores de $\mathrm{pH}$. A Tabela 4 mostra que os maiores valores de frequiência de ocorrência para estes microrganismos foram detectados nos pontos CM, D3 e BS, onde os valores médios de $\mathrm{pH}$ variaram de 2,8 a 3,9. Sendo assim, esses resultados concordaram com o esperado, uma vez que o $\mathrm{pH}$ de crescimento dessas espécies está numa faixa de 1,2 a 4,0 (GOLOMZIK IVANOV, 1965). Já os baixos valores obtidos para íon ferroso no presente estudo, podem ter influenciado a ocorrência de A. ferrooxidans, visto que, dentre as amostras líquidas procedentes da UTM, a maior freqüência de A. ferrooxidans foi observada no ponto D3, o qual apresentou o maior valor médio de íon ferroso $(3,30 \mathrm{mg} / \mathrm{L})$.

Pode-se observar também que houve correlação entre os valores obtidos para o potencial de óxido-redução (Fem) das amostras, que variaram de $+281,9 \mathrm{mV} \mathrm{a}+$ $554,6 \mathrm{mV}$, e a incidência de A. ferrooxidans e A. thiooxidans, uma vez que, de acordo com a literatura, valores de potencial redox de +340 $\mathrm{mV} \mathrm{a}+540 \mathrm{mV}$ têm sido encontrados durante extração de urânio, na presença de Acidihiobacillus spp. oxidante de ferro (EVANGELOU; ZHANG, 1995).

\subsection{Contagem de bactérias heterotróficas}

A Tabela 5 mostra que os valores para a contagem de bactérias heterotróficas em amostras da UTM variaram de $2,1 \times 10^{2}$ $\mathrm{UFC} / \mathrm{mL}(\mathrm{BS})$ a $4,2 \times 10^{3} \mathrm{UFC} / \mathrm{mL}(\mathrm{CM})$. O valor encontrados na $\mathrm{CM}$ foi comparável ao registrado na amostra do ponto 14, indicando que bactérias heterotróficas são resistentes a elevadas concentrações de espécies químicas estáveis e radioativas, bem como pH ácido.

Tabela 5 - Valores médios de bactérias heterotróficas (UFC/mL).

\begin{tabular}{cc}
\hline $\begin{array}{c}\text { Pontos de } \\
\text { amostragem }\end{array}$ & $\begin{array}{c}\text { Bactérias heterotróficas } \\
(\text { UFC } / \mathbf{m L})\end{array}$ \\
\hline CM & $4,2 \times 10^{3}$ \\
D3 & $1,8 \times 10^{3}$ \\
$\mathbf{1 4}$ & $3,7 \times 10^{3}$ \\
BS & $2,1 \times 10^{2}$ \\
\hline
\end{tabular}


Tabela 4 - Valores médios obtidos para variáveis químicas e microbiológicas nas amostras da UTM, apresentando correlação entre Fe e Acidithiobacillus).

\begin{tabular}{ccccccc}
\hline $\begin{array}{c}\text { Pontos de } \\
\text { Amostragem }\end{array}$ & $\mathbf{p H}$ & $\begin{array}{c}\mathbf{F e m} \\
(\mathbf{m V})\end{array}$ & $\begin{array}{c}\mathbf{F e}^{\mathbf{2 +}} \\
(\mathbf{m g} / \mathbf{L})\end{array}$ & $\begin{array}{c}\mathbf{F e}^{3+} \\
(\mathbf{m g} / \mathbf{L})\end{array}$ & $\begin{array}{c}\text { A.ferroxidans } \\
(\mathbf{N M P} / \mathbf{m L})\end{array}$ & $\begin{array}{c}\text { A.thiooxidans } \\
(\mathbf{N M P / m L})\end{array}$ \\
\hline $\mathbf{C M}$ & 2,8 & 554,6 & 0,685 & 2,54 & & \\
$\mathbf{D 3}$ & 2,92 & 466,6 & 3,30 & 7,12 & 0,9 & 1,4 \\
$\mathbf{1 4}$ & 6,37 & 281,9 & $<0,2$ & 0,831 & $<0,3$ & $<, 5$ \\
$\mathbf{B S}$ & 3,9 & 375,1 & - & - & 0,4 & 4,3 \\
\hline
\end{tabular}

\subsection{Concentração de nutrientes}

Os valores médios da concentração de nutrientes estão representados na Tabela 6. Pode-se observar que os maiores valores do íon amônio foram encontrados nos pontos CM e D3, correspondendo a 106,4 $\mu \mathrm{g} \mathrm{L}^{-1}$ e 93 $\mu \mathrm{g} \mathrm{L}^{-1}$, respectivamente. Estes pontos também apresentaram maiores valores de fósforo total e nitrogênio total, sendo encontrado $56,15 \mu \mathrm{g}$ $\mathrm{L}^{-1}$ de fósforo total no ponto D3 e $700 \mu \mathrm{g} \mathrm{L}^{-1}$ de nitrogênio total na CM.

Tabela 6 - Valores médios de concentração de nutrientes: amônio, silicato, nitrato, nitrito, fosfato total dissolvido, fosfato inorgânico, fósforo total e nitrogênio total.

\begin{tabular}{lrrr}
\hline \multirow{2}{*}{ Nutriente } & \multicolumn{3}{c}{ Pontos de } \\
& Amostragem \\
& \multicolumn{1}{c}{ DM } & \multicolumn{1}{c}{ D3 } & \multicolumn{1}{c}{$\mathbf{1 4}$} \\
\hline Amônio $(\mu \mathrm{g} / \mathrm{L})$ & 93,4 & 106,4 & 14,7 \\
Silicato $(\mathrm{mg} / \mathrm{L})$ & 1,28 & 2,78 & 3,21 \\
Nitrato $(\mu \mathrm{g} / \mathrm{L})$ & 38,7 & 187,4 & 15,5 \\
Nitrito $(\mu \mathrm{g} / \mathrm{L})$ & 29,6 & 19 & 0 \\
Fosfato Total Dissolvido & 1,98 & 11,5 & 0 \\
$(\mu \mathrm{g} / \mathrm{L})$ & 2,45 & 3,06 & 0 \\
Fosfato Inorgânico $(\mu \mathrm{g} / \mathrm{L})$ & 21,76 & 56,15 & 6,16 \\
Fósforo Total $(\mu \mathrm{g} / \mathrm{L})$ & 700 & 607 & 470 \\
Nitrogênio Total $(\mathrm{mg} / \mathrm{L})$ & & &
\end{tabular}

No ponto D3 também foi encontrada maior concentração de nitrato, registrando $187,4 \mu \mathrm{g} \mathrm{L}^{-1}$ do nutriente. Em relação as concentrações de silicato, nitrito, fosfato orgânico e fosfato total dissolvido, os pontos de amostragem apresentaram baixas concentrações desses nutrientes, observandose que o ponto 14 apresentou maior valor para silicato, ou seja, 3,21 $\mu \mathrm{g} \mathrm{L}^{-1}$. Os maiores valores de fosfato inorgânico e fosfato total dissolvido foram encontrados no ponto D3.

\section{CONCLUSÃO}

Os números de A. ferrooxidans e A. thiooxidans determinados neste estudo provavelmente podem ter sido subestimados na amostra sólida procedente da BS, uma vez que estes microrganismos podem fixar-se a partículas minerais, especialmente à pirita em amostras sólidas, com tal aderência que torna difícil sua liberação mesmo utilizando intensa agitação (SOUTHAM; BEVERIDGE, 1992).

No presente estudo observou-se que, para todas as amostras avaliadas, $\mathrm{o} \mathrm{pH}$ foi superior a 2,0 e, de acordo com Campos (2006), em meio ambiente apresentando $\mathrm{pH}$ maior que 2,0, as reações de lixiviação da pirita envolvem a oxidação de íons Fe (II) pelo ar e são aceleradas juntamente com a oxidação microbiana da pirita, levando à formação de precipitados de Fe (III), tais como hidróxidos sobre a pirita. Também, as formas nitrogenadas, fosfatadas e silicato foram analisadas na UTM/INB e represa das Antas. Segundo Carpenter (1988) baixas concentrações de nutrientes podem limitar a 
produtividade primária em lagos, rios e reservatórios, uma vez que sua disponibilização em quantidades adequadas é essencial para o desenvolvimento de organismos aquáticos. Em relação à concentração de metais no efluente proveniente da UTM/INB, pode-se observar que, os efluentes tratados e lançados no ambiente (ponto 14), estiveram de acordo com os limites fixados pelas legislações vigentes para água Classe II (CONAMA 2005).

Foi possível observar também que, os altos valores de Fem, associados aos baixos valores de $\mathrm{pH}$ estiveram relacionados as maiores incidências e valores de contagens de A. ferrooxidans e A. thiooxidans. Os pontos CM, D3, e BS, quando comparados simultaneamente, mostraram ser os principais locais de ocorrência de DAM e ação de bactérias biolixiviantes na UTM/INB e devem ser considerados pontos críticos, frente a uma possível ação de descomissionamento.

\section{REFERÊNCIAS}

\section{AMERICAN PUBLIC HEALLTY} ASSOCIATION (APHA). Standart methods for the examination of water and wastewater. 18 ed. Washington: American Water Works Association and Water Association Federation, 1992.

ANNUAL BOOK OF ASTM STANDARDS. Analytical Methods (Spectroscopy; Chromatography; Computerized Systems). Philadelphia: American Society for Tsting and Materials, 1980. Part 42. 646p.

ANTUNES, S. C.; PEREIRA, R.; GONÇALVES, F. Evaluation of the Potential Toxicity (acute and chronic) of Sediments from Abandoned Uranium Mine Ponds, Journal Soils Sediments, v. 7, n. 6, p.368376, 2007.
BRAGA, B.; REBOUÇAS, A.C.; TUNDISI, J. G. Águas Doces do Brasil: Capital Ecológico, Uso e Conservação. 3 ed. São Paulo: Editora Escrituras. 748p, 2006

CAMPOS, M. B. Ocorrência e Futuação de Acidithiooacillus spp. em Efluentes de Mina de Urânio, Caldas - MG. 40 f. Trabalho de Conclusão de Curso (Monografia) - Centro Universitário Fundação de Ensino Octávio Bastos, São João da Boa Vista, São Paulo, 2006.

CAMPOS, M. B.; AZEVEDO, H.; NASCIMENTO, M. R. L.; ROQUE, C. V.; RODGER, S. Environmental assessment of water from a uranium mine (Caldas, Minas Gerais State, Brazil) in a descommissioning operation. Environmental Earth Science, 2010.

CARPENTER, S. R. Complex interections in lake communities. New York: SpringerVerlag, 283 p. 1988.

CIPRIANI, M. Mitigação dos impactos sociais e ambientais decorrentes do fechamento definitivo de minas de urânio, 2002. 332f. Tese (Doutorado) - Faculdade de Engenharia, Universidade de Campinas, Campinas, 2002.

EVANGELOU, V.P.; ZHANG, Y.L. A review: pyrite oxidation mechanisms and acid mine drainage prevention. Critical Reviews Environmental Science Technology, 25(2): 141-199, 1995.

FUKUMA, H. T.; DE NADAI FERNANDES, E. A.; NASCIMENTO, M. P.; QUINELATO, A. L. Separation and spectrophotometric determination of thorium contained in uranium concentrates. Journal of Radial and Nuclear Chemistry, v.248, p.549-533, 2001. 
GARCIA, Jr. O. Estudos da biolixiviação de minérios de urânio por Acidithiobacillus ferroxidans. Campinas, UNICAMP, $261 \mathrm{p}$. (Tese de Doutorado). 1989.

GOLOMZIK, A.I.; IVANOV, V.I. Adaptation of Thiobacillus ferrooxidans increased hydrogen ion and iron concentrations. Mikrobiologyia, 34: 465468, 1965.

GOLTERMANN, H.L., CLYMO, R.S., OHNSTAD, M.AM. Methods for physical and chemical analysis of freshwaters. $2^{\text {nd }}$ ed. Oxford: Blackwell Scientific Publications, 213p. 1978

KOROLEFF, F. Determinations of nutrients. In: GRASSHOFF, K., (Ed). Methods of sea water analysis. Verlag Chemie Weinhein. 117-181p. 1976

LYEW, D.; SHEPPARD, J. Use of conductiivity to monitor the treatment of acid mine drainage by sulfate-reducing Bacteria. Water Research, v. 35, n.8, p.2081-2086, 2001.

MACKERETH, F. J. H.; HERON, J.; TALLING, J. F. Water analysis: Some revised methods for limnologists. Kendall: Titus Wilson \& Sons Ltd, 117p. 1978. (Freshwater Biological Association. Scientific Publication, n. 36)

SCHIPPERS, A.; HALLMANN, R.; WENTZIEN, S.; SAND, W. Microbial diversity in uranium mine waste heaps. Applied Envirimental Microbiology. 61 (8): 2930-35, August. 1995.

SOUTHAM, G.; BEVERIDGE, T.J. Enumeration of thiobacilli within pHneutral and acidic mine tailings and their role in the development of secondary mineral soil. Applied Environmental Microbiology, 58(6): 1904-12, June, 1992.

STRICKLAND, J. D. H.; PARSONS, T. R. A manual of seawater analysis. Bulletin of the Fisheries Research Board of Canada, v.125, p. 1-18, 1960.

TEIXEIRA, C. M.; RAMIRES, I.; GARCIA, Jr. O.; GUASTALDI, A. C. Aplicação de técnicas eletroquímicas da dissolução oxidativa da covelita (CUS) poe Acidithiobacillua ferroxidans. Quim. Nova, Vol. 25, No. 1, 20-26. 2002.

TEIXEIRA, C.; TUNDISI, J. G.; KUTNER, M. B. Plankton studies in a mangrove II. The standing stock and some ecological factors. Bolmish Institute Oceanography, v. 24, p.23-41, 1965.

TUOVINEN, O. H.; KELLY, D. P. Studies on the growth of Thiobacillus $A$. ferrooxidans. I. Use of membrane filters and ferrous iron agar to determine viable number, and comparison ${ }^{14} \mathrm{CO}_{2}$-fixation and iron oxidation as measures of growth. Archives Microbiology, 88: 285-98, 1973.

VALDERRAMA, J. C. The simultaneous analysis of total nitrogen and phosphorous in natural waters. Marc. Chem., v. 10, p. 109122, 1982.

\section{AGRADECIMENTOS}

Os autores agradecem à Comissão Nacional de Energia Nuclear pelo auxílio para realização da pesquisa. 